ĐTÐ cao hơn so với nhóm không sốt (20,9\% so với $0 \%$ ) (bảng 5). Như vậy, bệnh nhân lọc máucó ĐTĐ có nguy cơ nhiếm khuẩn huyết cao hơn so với các bệnh nhân không có ĐTĐ. Điều này cũng được nhận thấy ở nhiều nghiên cứu khác, theo Helene bệnh nhân bị ĐTĐ nguy cơ bị nhiễm khuẩn cao gấp 3 đến 4 lần so với người bình thường[7]. Nghiên cứu của Lê Ngọc Hà tỷ lệ sốt ở bệnh nhân ĐTĐ là 19,6\% [4]. THA là bệnh lý nền hay gặp nhất (63,5\%), không có sự khác biệt giữa 2 nhóm. Mức độ thiếu máu hay gặp nhất là thiếu máu vừa chiếm $50 \%$ và năng chiếm $34,6 \%$. Không có sự khác biệt về mức độ thiếu máu giữa 2 nhóm, do thiếu máu gặp hầu hết ở các bệnh nhân suy thận mạn. Chì số albumin huyết thanh trung bình của nhóm sốt $(31,82 \pm$ $6,73)$ thấp hơn so với nhóm không sốt $(32,79 \pm$ $7,04)$. Sự khác biệt không có ý nghĩa thống kê. Nhiêu tác giả trong nước và ngoài nước cũng ghi nhận tình trạng suy dinh dưỡng với albumin huyết thanh giảm sẽ làm tăng nguy cơ nhiễm trùng [4].

\section{KẾT LUÂN}

Nhiễm trùng liên quan đến catheter trên bệnh nhân lọc máu cấp cứu có thể ở bất cứ lứa tuổi nào, thường gặp ở nam. Vị trí đặt hay gặp nhiễm trùng nhất là catheter tĩnh mạch đùi phải, biểu hiện tại chỗ hay gặp là chảy dịch, vi khuẩn gây bểnh thường gặp là $\mathrm{S}$. aureus. Cần chú ý hướng dẩn bệnh nhân vệ sinh và chăm sóc catheter khi có catheter lọc máu.

\section{TÀI LIỆU THAM KHẢO}

1. Lemaire $X$, Morena $M$, Leray-Moragués $H$, et al. Analysis of risk factors for catheter related bacteremia in 2000 permanent dual catheters for hemodialysis. Blood Purif. 2009;28(1):21-28. doi: $10.1159 / 000210034$

2. Maki DG, Kluger DM, Crnich CJ. The risk of bloodstream infection in adults with different intravascular devices: a systematic review of 200 published prospective studies. Mayo Clin Proc. 2006;81(9):1159-1171. doi:10.4065/81.9.1159

3. Su Văn Na Mê Thy Phan Khăm. Đánh giá hiêu quả của một số đường dẫn máu ra ngoài cơ thể để lọc máu. Luận văn tiến sỹ, Trường Đại Học Y Hà Nội. 2001:1-27, 66, 70

4. Lề Ngọc Hà, Đố Gia Tuyển, Khảo sát tình trạng nhiếm trùng liên quan đên đường vào mạch máu tạm thời trong lọc máu cấp cứu ở bệnh nhân suy thận giai đoạn cuối Luận văn thạc sỹ், Trường Đại Học Y Hà Nội. 2015

5. WeydeW, $\mathbf{W} .$, KlingerM,Morawsleaz, Prolouged use of the femoral catheter as a temporary access for hemodialysis. Przegleki 54, 1997

6. CanaudBernard, Haemodialysis catheter-related infection: time for actions. Nephrol Dial Transplantation, 1994.

7. Helen Caivet MD, T.T., Yoshikawa MD, Infections in diabetes. 2001: p. 407-418.

\title{
ĐÁNH GIÁ KẾT QUẢ ĐIỀU TRỊ UNG THƯ PHỔI KHÔNG TẾ BÀO NHỎ DI CĂN NÃO BẰNG XẠ PHẪU GAMMA KNIFE VÀ HÓA TRI PHÁC Đồ PEMETREXED-CARBOPLATIN (PC)
}

\section{TÓM TẮT}

Mục tiêu: Nghiên cứu này nhằm mô tả một số đặc điểm lâm sàng, cận lâm sàng ở bệnh nhân ung thư phổi không tế bào nhỏ di căn não được điều trị bằng xạ phẫu Gamma Knife kết hợp hóa trị phác đồ Pemetrexed-Carboplatin tại Bệnh viện $K$ và Trung tâm Y học hạt nhân và Ung bướu, Bệnh viện Bạch Mai và đánh giá kết quả điều trị của nhóm bệnh nhân trên. Đối tượng và phương pháp nghiên cứu: Nghiên cứu mô tả hồi cứu kết hợp tiến cứu trên 65 bệnh nhân được chẩn đoán xác định là ung thư phổi không tế

\footnotetext{
${ }^{1}$ Bệnh viện Phổi Hải Dương

2Trường Đai hoc Y Hà Nội

${ }^{3}$ Bệnh viện đa khoa Tâm Anh

Chịu trách nhiệm chính: Nguyễn Công Đại

Email: mandini1987@gmail.com

Ngày nhân bài: 21.6.2021

Ngày phản biên khoa hoc: 16.8 .2021

Ngày duyệt bài: 23.8.2021
}

\section{Nguyễn Công Đại ${ }^{1}$, Nguyễn Văn Hiếu ${ }^{2}$, Vũ Hũu Khiêm ${ }^{3}$}

bào nhỏ không vảy di căn não, được điều trị bằng xa phẫu Gamma Knife kết hợp hóa trị phác đồ Pemetrexed-Carboplatin tại Bệnh viện $K$ và Trung tâm Y học hạt nhân và Ung bướu, Bệnh viện Bạch Mai từ tháng 1/2018 đến tháng 7/2021. Kết quả: Tuổi trung bình là $58,3 \pm 9,2$ tuổi, nam giới chiếm tỷ lệ $86,2 \%$, đặc điểm lâm sàng: hội chứng tăng áp lực nội sọ $(72,3 \%)$, ho khan $(61,5 \%)$, không có triệu chứng thần kinh $(18,5 \%)$. Đặc điêm hình ảnh MRI sọ não: u ở bán cầu đại não $(66,2 \%), 3$ u $(44,6 \%)$, kích thước u não di căn trên $10 \mathrm{~mm}(89,2 \%)$. Tỷ lệ đáp ứng khách quan toàn bô là $35,4 \%$, đáp ứng k̇hách quan tai não là $70,7 \%$, đáp ứng khách ngoài não là 36,9\%.Tỷ lệ kiểm soát bênh tai não là $90,7 \%$. Trung vi thời gian sống thêm bệnh không tiến triển (PFS) là 10,3 tháng. Trung vị thời gian sống thêm không tiến triển tại não là 10,8 tháng. Tác dụng phụ hay gặp là thiếu máu $(49,2 \%)$, buồn nôn $(40 \%)$, nôn $(20 \%)$, tăng men gan $(12,3 \%)$. Kết luận: Xạ phâuu Gamma Knife kết hợp hóa trị phác đồ Pemetrexed-Carboplatin là phương pháp điêu trị hiệu quả tốt trong ung thư phổ không tế bào nhỏ di 
căn não với độ an toàn cao.

Tư khóa: Ung thư phổi không tế bào nhỏ, u não di căn, hóa trị, xạ phẫu gamma knife, pemetrexed.

\section{SUMMARY}

EVALUATING THE RESULT OF GAMMA KNIFE RADIOSURGERY CONCURRENT WITH PEMETREXED AND CARBOPLATIN COMBINATION (PC) FOR BRAIN METASTASES OF NON SMALL CELL LUNG CANCER

Purpose: This study aimed at evaluating clinical, subclinical characteristics and resuls of treatment on patients who underwent Gamma Knife radiosurgery concurrent with Pemetrexed and Carboplatin conbination for brain metastases of non small cell lung cancer (NSCLC) at K Hospital and the Nuclear Medicine and Oncology Center, Bach Mai Hospital. Patients andMethod: Retrospective combination prospective descriptive cross sectionnal study on 65 NSCLC non squamous cell with brain metastases were underwent Gamma Knife radiosurgery concurrent with Pemetrexed and Carboplatin conbination at $\mathrm{K}$ Hospital and the Nuclear Medicine and Oncology Center, Bach Mai Hospital from January 2018 to July 2021. Results: The mean age was $58,3 \pm 9,2$ years old, males accounted for 86,2\%. Clinical characteristics: intracranialhypertension $(72,3 \%)$, dry cough $(61,9 \%)$, no mental symptoms $(18,5 \%)$. MRI features: tumors located in hemisphere $(66,2 \%)$, three tumor $(44,6 \%)$, above $10 \mathrm{~mm}$ in diameter of the brain metastases $(89,2 \%)$. The overall response rate (ORR) was $35,4 \%$, the objective cerebral response rate was $70,7 \%$, the extracerebral response rate was $36,9 \%$. The disease control rate (DCR) of cerebral lesions was $90,7 \%$. The median of progression free survival (PFS) was 10,3 months. The median progression-free survival of brain metastases was 10,8 months.Common toxicity were anemia $(49,2 \%)$, nausea $(40 \%)$, vomiting $(20 \%)$, hepatic insufficiency $(12,3 \%)$. Conclusions: Gamma Knife radiosurgery concurrent with Pemetrexed and Carboplatin combination is effective in treating brain metastases of non small cell lung cancer with a high safety. Keywords: non small cell lung cancer, brain metastases, chemotherapy, gamma knife radiosurgery, pemetrexed.

\section{I. ĐĂT VẤN ĐỀ}

Ung thư phổi (UTP) là một trong những loai ung thư phổ biến nhất và là nguyên nhân gây tử vong do ung thư hàng đầu trên thế giới, trong đó ung thư phổi không tế bào nhỏ (UTPKTBN) chiếm khoảng $85 \%$ các trường hợp ung thư phổi. Đa số bệnh nhân UTPKTBN được chẩn đoán bệnh khi đã có di căn xa không có khả năng phẫu thuật, trong đó căn não chiếm tỷ lệ cao. Di căn não là một nguyên nhân quan trong gây bệnh tật và tử vong ở bệnh nhân UTP, dẫn đến các triệu chứng thần kinh, giảm chức năng và cảm xúc của bệnh nhân cùng với một gánh nặng đáng kể cho gia đình và xã hội. Điều trị UTPKTBN di căn não là điều trị đa mổ thức phối hợp giữa các phương pháp kiểm soát tại não như phẫu thuật, xạ toàn não, xạ phẫu lập thể với các phương pháp điều trị toàn thân như hóa trị, điều trị đích, liệu pháp miễn dịch. Phương pháp xạ phẫu gamma knife cho thấy tỷ lệ kiểm soát ù não di căn hiệu quả hơn và an toàn hơn so với phương pháp xạ toàn não ${ }^{1}$. Đồng thời, đối với bênh nhân UTPKTBN không vảy di căn não không có đột biến phân tử, hóa trị bộ đôi Pemetrexed-platinum (Cisplatin, Carboplatin) giúp tăng tỷ lệ đáp ứng chung cũng như tỷ lệ đáp ứng tại não và kéo dài thời gian sống thêm cao hơn so với nhiều phác đồ hóa trị khác ${ }^{2}$. Hiên nay ở bệnh nhân UTPKTBN không vảy di căn nã̃o không có đột biến phân tử, không phù hợp điều trị miễn dichthì chiến lược điều trị kết hợp giữa xa phẫuGamma Knife với hóa trị phác đồ Pemetrexed-Carboplatin là lựa chọn phổ biến. Tuy nhiên, còn ít công trình khoa học trong nước nghiên cứu về kết quả điều tri ở nhóm bệnh nhân này.Vì vậy, chúng tôi tiến hành đề tài "Đánh giá kết quả điều trị ung thư phổi không tế bào nhỏ di căn não bằng xạ phẫu Gamma Knife và hóa trị phác đồ Pemetrexed-Carboplatin (PC) "nhằmhai mục tiêu: Mô tả một số đặc điểm lâm sàng, cận lâm sàng củabệnh nhân ung thư phổi không tế bào nhỏ di căn nãođược điều trị bằng xạ phẫu Gamma Knife kết hợp hóa chấtphác đồ Pemetrexed-Carboplatin tại Bệnh viện $K$ và Trung tâm Y học hạt nhân và Ung bướu, Bệnh viện Bạch Mai và Đánh giá kết quả điều trị của nhóm bệnh nhân trên.

\section{II. ĐỐI TƯỢNG VÀ PHƯƠNG PHÁP NGHIÊN CỨU}

\section{1 Đối tượng nghiên cứu}

- Gồm 65 bệnh nhân được chẩn đoán xác định bằng mô bệnh học của u nguyên phát là UTP loại ung thư phổi không tế bào nhỏ, không vảy. Không có đột biến gen EGFR, ALK, ROS 1.

- Trên phim MRI có hình ảnh tổn thương di căn não điển hình (ngấm thuốc dạng viền sau tiêm, phù não quanh $u$ ), từ $1-3 \mathrm{u}$, đường kính $u$ lớn nhất $\leq 30 \mathrm{~mm}$, không có di căn dưới nhện.

- Chỉ số toàn trang PS từ $0-2$ theo thang điểm ECOG hoặc chỉ số Karnosky $\geq 60$. Chức năng gan thận, tủy xương trong giới hạn bình thường.

- Bệnh nhân được điều trị lần đầu. Tất cả các bệnh nhân được điều trị bằng xa phẫu gamma knife kết hợp hóa tri phác đồ PemetrexedCarboplatin tại Bệnh viện $\mathrm{K}$ và Trung tâm $\mathrm{Y}$ học hạt nhân và Ung bướu Bệnh viện Bạch Mai.

\subsection{Phương pháp nghiên cứu}

Thiết kế nghiên cứu: Nghiên cứu mô tả cắt ngang hồi cứu kết hợp tiến cứu.

Cỡ mẫu và phương pháp chọn mẫu: Lấy 
mẫu thuận tiện (tất cả các bệnh nhân đủ tiêu chuẩn trên được điêu trị từ tháng 1/2018 7/2021 tại Bệnh viện $K$ và Trung tâm $Y$ học hạt nhân và Ung bướu, Bệnh viện Bạch Mai.

Các biến số, chỉ số:

- Một số đặc điểm lâm sàng và cận lâm sàng: Tuổi, giới, triệu chứng lâm sàng, đặc điểm về u não di căn trên MRI.

- Đánh giá đáp ứng điều trị: bao gồm đáp ứng hoàn toàn, đáp ứng một phần, bệnh ổn định, bệnh tiến triển (Theo tiêu chuẩn RECIST 1.1). Đánh giá đáp ứng tại não.

- Đánh giá thời gian sống thêm bệnh không tiến triển, thời gian sống thểm bệnh không tiến triển tại não.

- Đánh giá các độc tính của phác đồ: độc tính trên hệ huyết học và độc tính ngoài hệ huyểt học.

Xử lý số liệu: bằng phầm mềm SPSS 16.0

\section{KẾT QUẢ NGHIÊN CỨU}

\section{1 Đặc điểm lâm sàng và cận lâm sàng}

3.1.1 Tuổi và giới. Độ tuổi trung bình là $58,3 \pm 9,2$. Nam chiếm tỷ lề $86,2 \%(56 / 65)$, nữ chiếm tỷ lệ 13,8\% (9/65). Tỷ lệ nam/nữ là 6,2/1.

3.1.2 Triệu chứng lâm sàng. Hội chứng tăng áp lực nội so ở 72,3\% các trường hợp, $18,5 \%$ khổng có các triệu chứng thần kinh. Ho khan ở $61,5 \%$ các trường hợp.

\subsection{3 Đặc điểm di căn não}

Bảng 1. Đặc điểm u não di căn trên MRI sọ não

\begin{tabular}{|c|c|c|}
\hline Đắc điểm u não di căn & $\mathbf{n}$ & Tỷ lệ \% \\
\hline \multicolumn{3}{|c|}{ Số u não di căn } \\
\hline 1 & 25 & 38,5 \\
\hline 2 & 11 & 16,9 \\
\hline 3 & 29 & 44,6 \\
\hline \multicolumn{3}{|c|}{ Vị trí u não } \\
\hline Bán cầu đại não & 43 & 66,2 \\
\hline Tiếu nã்o & 6 & 9,2 \\
\hline Bán câu đại não và tiếu não & 16 & 24,6 \\
\hline \multicolumn{3}{|c|}{ Đường kính u não lớn nhất (mm) } \\
\hline$<10$ & 7 & 10,8 \\
\hline $10-20$ & 29 & 44,6 \\
\hline $20-30$ & 29 & 44,6 \\
\hline
\end{tabular}

Nhân xét: Đa số bệnh nhân di căn não 3 u $(44,6 \%)$, vị trí u não di căn hay gặp ở bán cầu đại não $(66,2 \%)$, phần lớn u não có đường kính lớn nhất $\geq 10$ mm (89,2\%).
3.2 Kết quả điêu trị

3.2.2 Tý lệ đáp ứng khách quan

Bảng 2. Tý lệ đáp ứng khách quan toàn bộ và tỷ lệ đáp ứng tại não

\begin{tabular}{|c|c|c|c|}
\hline \multirow{2}{*}{$\begin{array}{c}\text { Đáp ứng } \\
\text { khách quan }\end{array}$} & $\begin{array}{c}\text { Tại não đậ đáp ứng theo vị trí } \\
(\%)\end{array}$ & $\begin{array}{c}\mathbf{N g o a ̀ i ~ n a ̃ o ~} \\
(\%)\end{array}$ & $\begin{array}{c}\text { Toàn bồ } \\
(\%)\end{array}$ \\
\hline $\begin{array}{c}\text { Đáp ứng hoàn } \\
\text { toàn }\end{array}$ & $11(16,9)$ & $0(0)$ & $0(0)$ \\
\hline $\begin{array}{c}\text { Đáp ứng một } \\
\text { phần }\end{array}$ & $35(53,8)$ & $24(36,9)$ & $23(35,4)$ \\
\hline Bệnh ốn định & $13(20)$ & $25(38,5)$ & $25(38,5)$ \\
\hline Bệnh tiến triến & $6(9,2)$ & $16(24,6)$ & $17(26,2)$ \\
\hline
\end{tabular}

Nhân xét: Tỷ lệ đáp ứng khách quan tại não là $70,7 \%$, trong đó $16,9 \%$ đáp ứng hoàn toàn. Tỷ lệ đáp ứng toàn bộ là 73,9\%.

\subsubsection{Thời gian sống thêm bệnh không} tiên triển

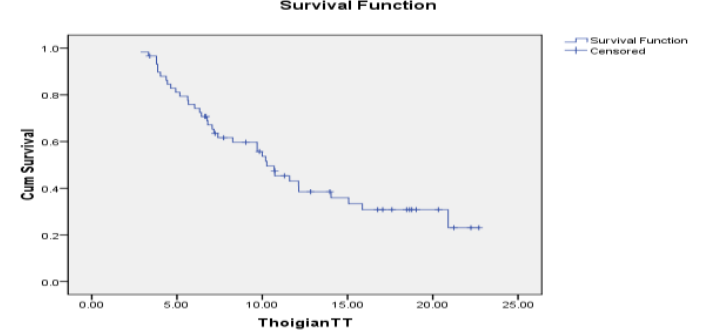

\section{Đồ thị 1. Thời gian sống thêm bệnh không tiến triến}

Nhận xét: Thời gian sống thêm bệnh không tiến triển (PFS) trung vị là 10,3 tháng. PFS tại các thời điểm 6 tháng là $75,9 \%$ và 1 năm là $43 \%$.

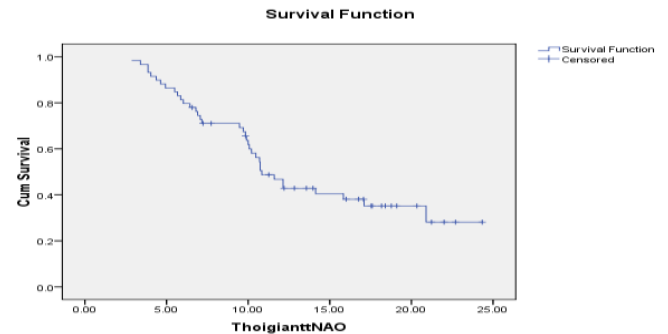

\section{Đồ thị 2. Thời gian sông thêm bệnh không tiến triển tại não}

Nhận xét: Thời gian sông thêm bệnh không tiến triển tại não trung vị là 10,8 tháng. PFS tại não ở các thời đđiểm 6 tháng là $81,4 \%$ và 1 năm là $46,8 \%$.

\subsection{4 Độc tính}

Bảng 3. Tác dụng không mong muốn

\begin{tabular}{|c|c|c|c|c|c|}
\hline \multirow{2}{*}{ Chỉ số } & \multicolumn{5}{|c|}{ Độc tính } \\
\cline { 2 - 6 } & Độ O (\%) & Độ 1 (\%) & Độ 2 (\%) & Độ 3 (\%) & Độ 4 (\%) \\
\hline Hận hậ tạo máu cầu & 93,8 & 6,2 & 0 & 0 & 0 \\
\hline Hạ BC hạt & 90,8 & 1,5 & 7,7 & 0 & 0 \\
\hline
\end{tabular}


VIETNAM MEDICAL JOURNAL N²2 - SEPTEMBER - 2021

\begin{tabular}{|c|c|c|c|c|c|}
\hline Thiếu máu & 50,8 & 35,4 & 9,2 & 4,6 & 0 \\
\hline Hạ tiếu câu & 98,5 & 1,5 & 0 & 0 & 0 \\
\hline \multicolumn{7}{|c|}{ Ngoài hê̂ tạo máu } \\
\hline Tăng men gan & 87,7 & 6,2 & 4,6 & 1,5 & 0 \\
\hline Tăng Creatinin & 96,9 & 3,1 & 0 & 0 & 0 \\
\hline Buôn nôn & 60 & 35,4 & 4,6 & 0 & 0 \\
\hline Nôn & 80 & 18,5 & 1,5 & 0 & 0 \\
\hline Tiêu chảy & 96,9 & 1,5 & 1,5 & 0 & 0 \\
\hline Viêm dạ dày & 96,9 & 3,1 & 0 & 0 & 0 \\
\hline
\end{tabular}

Nhận xét: Các tác dụng phụ hay gặp là thiếu máu (49,2\%), buôn nôn (40\%), nôn (20\%), tăng men gan (12,3\%), hạ bạch cầu hạt (9,2\%). 6,1\% bệnh nhân có tác dụng phụ độ 3 .

\section{BÀN LUẦN}

4.1 Một số đặc điểm lâm sàng và cận lâm sàng. Trong nghiên cứu của chúng tôi, tuổi mắc bệnh trung bình là $58,3 \pm 9,2$ tuổi. Kết quả nghiên cứu này cũng phù hợp với kết quả của các tác giả trong và ngoài nước về UTPKTBN di căn não như của tác giả Phạm Văn Thái (2015) là $58,8 \pm 10,3$; nghiên cứu FRAME (2015) cho thấy tuổi trung bình của nhóm bệnh nhân UTPKTBN di căn não là 58 tuổi thấp hơn tuổi trung bình của tất cả bênh nhân UTPKTBN giai đoạn muộn là 64 tuổi ${ }^{2,3}$. Như vậy độ tuổi trung bình của bệnh nhân UTPKTBN di căn não có xu hướng thấp hơn so với bệnh nhân UTPKTBN nói chung. UTPKTBN di căn não gặp chủ yếu ở nam giới, chiếm tỷ lệ $86,2 \%$, tỷ lệ nam/nữ là 6,2/1. Kết quả này phù hợp với các nghiên cứu của Phạm Văn Thái (2015) là 70,4\%, tỷ lệ nam/nữ = $2,4 / 1$. Nghiên cứu của chúng tôi cho thây đa số bệnh nhân có biểu hiên hội chứng tăng áp lực nôi sọ, chiếm 72,3\% với các triệu chứng như đau đầu, buồn nôn, nhìn mờ và có $18,5 \% \mathrm{BN}$ không có biểu hiện triệu chứng thần kinh. Ho khan là triệu chứng hô hấp phổ biến nhất với tỷ lệ $61,5 \%$. Kết quả này tương tự nghiên cứu của Phạm Văn Thái (2015)3.

Phân tích đăcc điểm di căn não trên phim chụp MRI sọ não, chúng tôi thấy đa số bệnh nhân có 3 u não di căn, chiếm tỷ lệ 44,6\%.Phần lớn u não có đường kính lớn nhất $\geq 10 \mathrm{~mm}$ với tỷ lệ $89,2 \%$, kết quả này cũng tương tự của Phạm Văn Thái (2015) là $96,3 \%^{3}$. Về vị trí, u não di căn hay gặp nhất ở hai bán cầu đại não với tỷ lệ $66,2 \%$. Nhiều nghiên cứu của các tác giả trong và ngoài nước cũng nhận thấy đa số u não di căn phân bố ở hai bán cầu đại não ${ }^{3,4}$. Điều này là do các tế bào ung thư di căn đến não theo đường máu (động mạch), tổng thể sự phân bố của các ổ di cằn não tương ứng với lưu lượng máu tương đối đến từng khu vực do các động mạch não phân phối, bán cầu đại não nhận lưu lượng máu lớn hơn cả.

\subsection{Kết quả điêu trị}

\subsubsection{Tỷ lê đáp ứng khách quan}

Về tỷ lệ đáp ứng khách quan toàn bộ: Kết quả nghiên cứu của chúng tôi cho thấy, tỷ lệ đáp ứng toàn bộ (ORR) là 35,4\%, tỷ lệ kiểm soát bệnh (DCR) là $73,9 \%$. Kết quả này cao hơn so với kết quả của nghiên cứu chỉ sử dụng hóa trị Pemetrexed-Carboplatin đơn thuần điều trị UTPKTBN. Nghiên cứu KEYNOTE - 021 nhánh hóa trị Pemetrexed - Carboplatin cho thấy ORR và DCR là $29 \%$ và $70 \% 5$. Điều này chứng tỏ rằng sự phối hợp giữa liệu pháp điều trị tổn thương u não di căn bằng xạ phẫu Gamma Knife với liệu pháp điều trị toàn thân bằng phác đồ Pemetrexed-Carboplatin làm tăng tỷ lệ đáp ứng toàn bộ và tỷ lệ kiểm soát bệnh so với hóa trị bộ đôi Pemetrexed - Carboplatin đơn thuần.

Về tỷ lệ đáp ứng khách quan ngoài não: tỷ lệ đáp ứng ngoài não là $36,9 \%$, tỷ lệ kiểm soát bệnh ngoài não là $75,4 \%$, tác giả Barlesi (2011) cũng cho kết quả tương tự với các tỷ lệ này lần lượt là $34,9 \%$ và $79,1 \%{ }^{6}$.

Về tỷ lệ đáp ứng khách quan tại não: nghiên cứu của chúng tôi cho thấy $70,7 \%$ bệnh nhân có đáp ứng khách quan tại não (16,9\% đáp ứng hoàn toàn, $53,8 \%$ đáp ứng một phần), tỷ lệ kiểm soát khối u tại não là $90,7 \%$. Kết quả này phù hợp với nhiêu nghiên cứu của các tác giả trong và ngoài nước về xạ phẫu GK điều trị tổn thương di căn não từ UTP với tỷ lệ kiểm soát khối u tại não từ $90-94 \%{ }^{3,7}$ và cao hơon hẳn các nghiên cứu chỉ sử dụng hóa trị PemetrexedPlatin đơn thuần ở nhóm bệnh nhân này như nghiên cứu của các tác giả Barlesi (2011) và Bailon (2012) với tỷ lệ đáp ứng tại não là $40 \%$ và $42,8 \%{ }^{6,8}$. Như vậy, mặc dù tỷ lệ ngấm qua hàng rào máu não của pemetrexed và carboplatin thấp nhưng khi kết hợp hóa trị bộ đôi này với xạ phẫu gamma knife đã làm tăng tỷ lệ đáp ứng và tỷ lệ kiểm soát khối u tại não so với chỉ điều trị bằng hóa trị bộ đôi đơn thuần.

4.2.2 Thời gian sống thêm bệnh không tiến triển. Trong nghiên cứu của chúng tôi, 
trung vị thời gian sống thêm bệnh không tiến triển (PFS) là 10,3 tháng, tỷ lệ sống thêm bệnh không tiến triển ở các thời điểm 6 tháng và 1 năm lần lượt là $75,9 \%$ và $43 \%$. Kết quả nghiên cứu của chúng tôi có phần cao hơn so với các nghiên cứu chỉ sử dụng hóa trị PemetrexedPlatin đơn thuần ở bệnh nhân UTPKTBN giai đoạn muộn. Theo nghiển cứu của Bailon (2012) trung vị sống thêm bệnh không tiến triển hóa trị Pemetrexed-Carboplatin đơn thuần là 7,3 tháng ${ }^{8}$. Theo nghiên cứu FRAME (2016) trung vị PFS hóa trị Pemetrexed-Platin đơn thuần là 4 tháng ${ }^{2}$. Như vậy, việc phối hợp hóa trị bộ đôi PemetrexedCarboplatin với xạ phẫu gamma knife giúp tăng thời gian sống thêm bệnh không tiến triển ở bênh nhân UTPKTBN di căn não.

Phân tích thời gian sống thêm bệnh không tiến triển tại não, chúng tôi thây trung vị thời gian sống thêm không tiến triển tại não là 10,8 tháng, tỳ lệ sống thêm không tiến triển tại các thời điểm 6 tháng và 1 năm là $81,4 \%$ và $46,8 \%$. Kết quả của chúng tôi cũng tương tự nghiên cứu của tác giả Phạm Văn Thái (2015) với trung vị PFS tại não là 10,8 tháng, tỷ lệ PFS tại các thời điểm 6 tháng và 1 năm là $90,1 \%$ và $30,2 \%{ }^{3}$.

\subsubsection{Tác dụng phù}

Vê độc tính trên hệ tạo máu: thiếu máu là tác dụng phụ hay gặp nhẩt, chiếm $49,2 \%$, tiếp đến là hạ bạch cầu hạt $(9,2 \%)$, hạ bạch cầu $(6,2 \%)$, hạ tiểu cầu ít gặp nhất $(1,5 \%)$. Phần lớn các tác dụng phụ chỉ ở mức độ nhẹ (độ 1 và 2 ), chỉ có $4,6 \%$ bệnh nhân có thiếu máu độ 3 , không ghi nhận độc tính trên hệ tạo máu độ 4. Kết quả nghiển cứu của chúng tôi cũng tương đồng với nghiên cứu KEYNOTE-021 (2016) nhánh hóa trị Pemetrexed - Carboplatin vơi 54\% bệnh nhân thiếu máu (độ 3 là 15\%); $8 \%$ hạ bạch cầu (độ 3 là $2 \%$ ); $13 \%$ giảm BC hạt (độ 3 là $3 \%) ; 12 \%$ giảm tiểu câu $(2 \% \text { độ } 4)^{5}$.

Về tác dụng phụ ngoài hệ tạo máu: buồn nôn là tác dụng phụ hay gặp nhất, chiếm $40 \%$, tiếp đến là nôn (20\%), tăng men gan $(12,3 \%)$, các tác dụng phụ khác ít gặp là tăng creatinin máu, viêm dạ dày, ỉa chảy $(3,1 \%)$, không có bệnh nhân nào dị ứng với các hóa chất nghiên cứu. Hầu hết các tác dụng phụ này đều ở độ 1 và độ 2 , chỉ có $1,5 \%$ ở độ 3 (tăng men gan). Kết quả nghiên cứu của chúng tôi cũng phù hợp với nghiên cứu KEYNOTE-021 (2016) nhánh hóa trị Pemetrexed - Carboplatin với tỷ lệ các độc tính ngoài hệ tạo máu tương ứng là: buồn nôn $(40 \%)$, nôn $(20 \%)$, tăng men gan $(12 \%)$, tiêu chảy $(12 \%)$, tăng creatinin $(6 \%)$, viêm dạ dày (5\%), hầu hết là độc tính độ 1 và độ $2^{5}$.

\section{KẾT LUẦN}

- Ung thư phổi không tế bào nhỏ di căn não thường gặp ở nam giới $(86,2 \%)$, tuổi trung bình là 58,3 tuổi. Đa số bệnh nhân có biểu hiện hội chứng tăng áp lực nội sọ $(72,3 \%)$ và ho khan $(61,5 \%)$, tuy nhiên $18,5 \%$ không có biểu hiện triệu chứng thần kinh.

- Phần lớn u não di căn ở bán cầu đại não $(66,2 \%)$, 3 u (44,6\%), kích thước trên $10 \mathrm{~mm}(89,2 \%)$.

- Tŷ lệ đáp ứng khách toàn bộ là $35,4 \%$, tỷ lệ đáp ứng khách quan tại não là $70,7 \%$, đáp ứng ngoài não là 36,9\%. Tỷ lệ kiểm soát khối u tại não đạt $90,7 \%$.

- Trung vị thời gian sống thêm không tiến triển là 10,3 tháng. Trung vị thời gian sống thêm không tiến triển tại não là 10,8 tháng.

- Đây là phác đồ điều trị an toàn với các tác dụng phụ hẩu hết ở độ 1 và độ 2 . Các tác dụng phụ hay gặp là thiếu máu $(49,2 \%)$, buồn nôn $(40 \%)$, nôn $(20 \%)$, tăng men gan $(12,3 \%)$.

\section{TÀI LIỆU THAM KHẢO}

1. Yamamoto $M$, Serizawa $T$, Shuto $T$, et al. Stereotactic radiosurgery for patients with multiple brain metastases (JLGK0901): a multi-institutional prospective observational study. The Lancet Oncology. 2014;15(4):387-395.

2. Moro-Sibilot D, Smit E, de Castro Carpeño J, et al. Non-small cell lung cancer patients with brain metastases treated with first-line platinumdoublet chemotherapy: Analysis from the European FRAME study. Lung cancer (Amsterdam, Netherlands). 2015;90(3):427-432.

3. Phạm Văn Thái. Nghiên cứu điều tri ung thư phổi khổng tế bào nhỏ di căn não bằng hóa xa trị [Luận văn tiến sĩ y học], Trường Đaii học Y Hà Nội; 2015.

4. Delattre JY, Krol G, Thaler HT, Posner JB. Distribution of brain metastases. Archives of neurology. 1988;45(7):741-744.

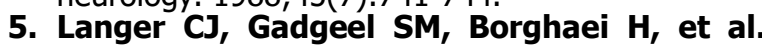
Carboplatin and pemetrexed with or without pembrolizumab for advanced, non-squamous nonsmall-cell lung cancer: a randomised, phase 2 cohort of the open-label KEYNOTE-021 study. The Lancet Oncology. 2016;17(11):1497-1508.

6. Barlesi $F$, Gervais $R$, Lena $H$, et al. Pemetrexed and cisplatin as first-line chemotherapy for advanced non-small-cell lung cancer (NSCLC) with asymptomatic inoperable brain metastases: a oncology: official journal of the European Society for Medical Oncology. 2011;22(11):2466-2470.

7. Gerosa $M$, Nicolato $A$, Foroni $R$, Tomazzoli $L$, Bricolo A. Analysis of long-term outcomes and prognostic factors in patients with non-small cell lung cancer brain metastases treated by gamma knife radiosurgery. Journal of neurosurgery. 2005; 102 Suppl:75-80.

8. Bailon $O$, Chouahnia $K$, Augier $A$, et al. Upfront association of carboplatin plus pemetrexed in patients with brain metastases of lung adenocarcinoma. Neuro-oncology. 2012;14(4):491-495. 